\title{
Creation of Surge Capacity by Early Discharge of Hospitalized Patients at Low Risk for Untoward Events
}

\author{
Gabor D. Kelen, MD, Melissa L. McCarthy, ScD, Chadd K. Kraus, MPH, Ru Ding, MSc, \\ Edbert B. Hsu, MD, MPH, Guohua Li, DrPh, Judy B. Shahan, RN, MBA, \\ James J. Scheulen, PA, and Gary B. Green, MD, MPH
}

\section{ABSTRACT}

Objectives: US hospitals are expected to function without external aid for up to 96 hours during a disaster; however, concern exists that there is insufficient capacity in hospitals to absorb large numbers of acute casualties. The aim of the study was to determine the potential for creation of inpatient bed surge capacity from the early discharge (reverse triage) of hospital inpatients at low risk of untoward events for up to 96 hours.

Methods: In a health system with 3 capacity-constrained hospitals that are representative of US facilities (academic, teaching affiliate, community), a variety $(\mathrm{N}=50)$ of inpatient units were prospectively canvassed in rotation using a blocked randomized design for 19 weeks ending in February 2006. Intensive care units (ICUs), nurseries, and pediatric units were excluded. Assuming a disaster occurred on the day of enrollment, patients who did not require any (previously defined) critical intervention for 4 days were deemed suitable for early discharge.

Results: Of 3491 patients, 44\% did not require any critical intervention and were suitable for early discharge. Accounting for additional routine patient discharges, full use of staffed and unstaffed licensed beds, gross surge capacity was estimated at 77\%, 95\%, and 103\% for the 3 hospitals. Factoring likely continuance of nonvictim emergency admissions, net surge capacity available for disaster victims was estimated at $66 \%, 71 \%$, and $81 \%$, respectively. Reverse triage made up the majority (50\%, 55\%, 59\%) of surge beds. Most realized capacity was available within 24 to 48 hours.

Conclusions: Hospital surge capacity for standard inpatient beds may be greater than previously believed. Reverse triage, if appropriately harnessed, can be a major contributor to surge capacity. (Disaster Med Public Health Preparedness. 2009;3(Suppl 1):S10-S16)

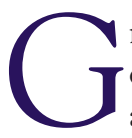
reat concern has arisen that there is insufficient capacity in hospitals/health systems to absorb large numbers of casualties during a catastrophic event. ${ }^{1-4}$ Many alleviating measures require external support ${ }^{2,5}$; however, hospitals are expected to manage without expectation of external aid for up to 96 hours. ${ }^{6}$

Surge capacity in the health care sector can be defined as the maximum potential augmentation of resources available to care for the influx of an unexpectedly large number of patients. ${ }^{7}$ Surge capacity can be augmented by increasing resources, decreasing demand, or redistributing assets. ${ }^{5,8}$ Means to achieve the latter 2 are the most efficient and cost-effective. From this perspective, the authors previously advanced the concept of reverse triage, wherein inpatients at low risk for untoward events would be discharged or transferred back to the community. This approach gives inpatients and disaster victims equal consideration for inpatient resources. ${ }^{9}$ A system of considering patient risk profiles for early discharge was recently published. ${ }^{8}$ We tested this concept and tried to determine the potential contribution to the augmentation of surge capacity during a catastrophic event in a large health system with 3 diverse hospitals.

\section{METHODS \\ Setting}

The institutions studied were a health system's 3 hospitals, 3 to $27 \mathrm{mi}$ apart, each serving a distinct area in Maryland. The hospitals were an inner-city university hospital, a mid-size teaching affiliate in a working class neighborhood, and a nonteaching community hospital located in a primarily affluent county (Table 1). Patients from these hospitals were prospectively sampled and surveyed as described below.

\section{Design}

Using a blocked randomized design controlling for day of week, inpatient units at the 3 hospitals were prospectively canvassed during a 19-week period ending in February 2006. The underlying precept was that 


\section{Capacity of 3 Study Hospitals During Observation Period}

$\begin{array}{lcccc}\text { Capacity } & \begin{array}{c}\text { Academic Center, } \\ \text { N (\%) }\end{array} & \begin{array}{c}\text { Teaching Affiliate, } \\ \text { N (\%) }\end{array} & \begin{array}{c}\text { Community Hospital, } \\ \text { N (\%) }\end{array} & \begin{array}{c}\text { Total Health System, } \\ \text { N (\%) }\end{array} \\ \text { Licensed beds } & 1017 & 355 & 260 & 1632 \\ \text { Total licensed beds on study services } & 691(68) & 258(73) & 190(73) \\ \text { Staffed study service beds } & 658(95) & 242(94) & 170(89) & 1141(70) \\ \text { Mean floor census on study services } & 540(82) & 198(82) & 139(82) & 19(14) \\ \text { Mean daily nonelective admissions* } & 34(6) & 28(14) & 4.1 & 819(82) \\ \text { Mean LOS of nonelective admissions, days* } & 4.5 & 3.7 & 4.1\end{array}$

LOS = length of stay.

*Study services only.

a major disaster occurred on the day of sampling at time $0\left(\mathrm{~T}_{0}\right)$. Patients present on sampled units at $T_{0}$ were followed for 4 days.

\section{Selection of Study Subjects}

There were 32,12, and 6 inpatient units identified as appropriate for study in the academic center, teaching affiliate, and community hospital, respectively. Pediatrics, newborn nursery, and ICUs were excluded because they were considered special populations. ${ }^{8}$ Units at the affiliate and community hospitals were sampled 2 and 4 times, respectively, as often as the academic center to ensure an adequate sample size.

At the time of unit sampling, all of the patients included in the morning census were identified for study. Demographic and clinical information were abstracted from the medical and billing records. Patients discharged on day $T_{0}$ were

TABLE 2

\section{Description of Study Population by Institution}

\begin{tabular}{|c|c|c|c|c|}
\hline & Academic Center & Teaching Affiliate & Community Hospital & Adjusted Total* \\
\hline \multicolumn{5}{|l|}{ Age } \\
\hline $35-44$ & $199(15 \%)$ & $184(17 \%)$ & $152(14 \%)$ & $534(15 \%)$ \\
\hline $45-54$ & $285(21 \%)$ & $167(16 \%)$ & $98(9 \%)$ & $637(18 \%)$ \\
\hline $55-64$ & $271(20 \%)$ & $143(13 \%)$ & $124(12 \%)$ & $606(17 \%)$ \\
\hline $65-74$ & $191(14 \%)$ & $141(13 \%)$ & $142(13 \%)$ & $482(14 \%)$ \\
\hline \multicolumn{5}{|l|}{ Sex } \\
\hline Female & $681(50 \%)$ & $572(54 \%)$ & $727(68 \%)$ & $1863(53 \%)$ \\
\hline Male & $671(50 \%)$ & $490(46 \%)$ & $350(32 \%)$ & $1628(47 \%)$ \\
\hline \multicolumn{5}{|l|}{ Ethnicity } \\
\hline White & $793(59 \%)$ & $729(69 \%)$ & $768(71 \%)$ & $2189(63 \%)$ \\
\hline Black & $485(36 \%)$ & $282(27 \%)$ & $215(20 \%)$ & $1103(32 \%)$ \\
\hline Elective or direct admission & $855(63 \%)$ & $360(34 \%)$ & $529(49 \%)$ & $1893(54 \%)$ \\
\hline \multicolumn{5}{|l|}{ Service } \\
\hline Medical & $710(53 \%)$ & $627(59 \%)$ & $350(32 \%)$ & $1803(52 \%)$ \\
\hline Surgical & $310(23 \%)$ & $174(16 \%)$ & $270(25 \%)$ & $753(22 \%)$ \\
\hline Oncology & $122(9 \%)$ & $0(0 \%)$ & $186(17 \%)$ & $273(8 \%)$ \\
\hline Obstetrics/Gynecology & $55(4 \%)$ & $87(8 \%)$ & $206(19 \%)$ & $243(7 \%)$ \\
\hline Psychiatry & $155(11 \%)$ & $174(16 \%)$ & $65(6 \%)$ & $419(12 \%)$ \\
\hline \multicolumn{5}{|l|}{ Disposition } \\
\hline Discharged & $505(37 \%)$ & $573(54 \%)$ & $639(59 \%)$ & $1542(44 \%)$ \\
\hline Discharged with service needs & $93(7 \%)$ & $62(6 \%)$ & $18(2 \%)$ & $208(6 \%)$ \\
\hline Transferred & $97(7 \%)$ & $139(13 \%)$ & $153(14 \%)$ & $332(10 \%)$ \\
\hline Died in hospital & $11(1 \%)$ & $8(1 \%)$ & $6(1 \%)$ & $28(1 \%)$ \\
\hline
\end{tabular}

\footnotetext{
*Adjusted for sampling frequency among sites.
} 
excluded because their hospital stay was complete and final disposition was established.

The following data were obtained for each patient: basic demographic information, arrival date, enrollment date (ie, $\mathrm{T}_{0}$ ) and discharge date, inpatient unit type (eg, medical, surgical), source of admission (nonelective vs elective), procedures, and interventions. The institutional review board approved the study.

\section{Safe Early Discharge}

An expert panel previously determined that patients with less than a $12 \%$ likelihood of a consequential medical event related to early hospital discharge were appropriate to consider for release during a disaster. ${ }^{8}$ Consequential medical event was defined as "unexpected death, irreversible impairment, or reduction in function." 8 Furthermore, medical events are consequential only if there is an in-hospital intervention with the potential to reverse or prevent additional deterioration. ${ }^{8}$ Because it would be unethical for the sole purpose of advancing science to measure medically consequential events by withholding treatments, a proxy was developed. The best proxy for a consequential medical event was determined as initiation or continuation of a critical intervention $(\mathrm{CI}){ }^{8}$

CIs were previously defined and weighted on a scale of 1 to 10 based on the risk of a bad outcome. ${ }^{7}$ For the purposes of analysis, CIs were placed in 3 categories: major importance (scale of 7-10), moderate importance (scale of 5-6), and lower importance (scale of $\leq 4$ ). Cls were further classified as discrete (ie, no continuous aspect, such as defibrillation, incision, drainage), or continuous, (eg, intravenous medications, cardiac monitoring).

\section{Analysis and Endpoints}

Patient evaluation of 4 days (approximately 96 hours) was based on experiences with recent major, high-impact disasters, showing that communities should expect to sustain medical services for 24 to 96 hours, ${ }^{10}$ and The Joint Commission revised standards requiring hospitals to identify stand-alone capabilities for the same period. ${ }^{6}$

Patients were considered to have a $\mathrm{CI}$ if a continuous $\mathrm{CI}$ initiated before $T_{0}$ remained in place or if any (continuous or discrete) CI occurred after $T_{0}$. CIs were ranked hierarchically by importance for patients experiencing more than 1 . $\mathrm{Pa}$ tients without a CI during the 4-day observation period were considered suitable for early discharge.

The total numbers of study beds for each hospital were ascertained (Table 1) to estimate the potential for creation of surge capacity in 2 categories. Daily gross surge capacity was determined by summing unoccupied staffed beds, opening unstaffed but licensed beds on the study services, discharging patients suitable for early release, and routinely discharging inpatients daily. To be conservative, we assumed availability
TABLE 3

\begin{tabular}{|c|c|c|}
\hline \multicolumn{3}{|c|}{ Frequency of Critical Interventions* } \\
\hline \multirow[t]{2}{*}{$\begin{array}{l}\text { Criticality }^{7} \\
\text { (Scale 1-10) }\end{array}$} & Critical Intervention Type & $\begin{array}{c}\text { Adjusted } \\
\text { Total }(\%)^{* *}\end{array}$ \\
\hline & \multicolumn{2}{|l|}{ Major Interventions } \\
\hline 10 & CPR or defibrillation & 7 \\
\hline 10 & Intubation/airway management & 158 \\
\hline 9 & Major surgery & 150 \\
\hline 9 & Cesarean section & 16 \\
\hline 8 & IV medication/pressors/fluids & 325 \\
\hline 8 & Oxygen requirement & 53 \\
\hline 8 & Burn care & 0 \\
\hline 8 & Cerebral bolt placement/monitoring & 2 \\
\hline \multirow[t]{2}{*}{7} & Dialysis & 34 \\
\hline & Thoracostomy tube & \\
\hline 7 & placement/requirement & 0 \\
\hline 7 & Noninvasive PPV & 38 \\
\hline \multirow[t]{3}{*}{7} & Thrombolytic administration & 0 \\
\hline & Subtotal & $783(40 \%)$ \\
\hline & \multicolumn{2}{|l|}{ Moderate Interventions } \\
\hline 6 & \multicolumn{2}{|l|}{ Blood or blood product } \\
\hline 6 & Other invasive procedure & 492 \\
\hline 6 & Psychiatric monitoring & 287 \\
\hline 6 & Cardiac catheterization & 26 \\
\hline 5 & Thoracentesis & 18 \\
\hline 5 & Wound care & 38 \\
\hline 5 & Central line placement/requirement & 4 \\
\hline 5 & $\begin{array}{l}\text { Minor surgery: incision and } \\
\text { drainage }\end{array}$ & 20 \\
\hline 5 & Parenteral nutrition requirement & 73 \\
\hline 5 & Paracentesis & 0 \\
\hline \multirow[t]{3}{*}{5} & Vaginal delivery & 36 \\
\hline & Subtotal & $1111(57 \%)$ \\
\hline & \multicolumn{2}{|l|}{ Less Critical Interventions } \\
\hline 4 & Arterial line requirement & 0 \\
\hline 4 & Lumbar puncture & 27 \\
\hline 3 & Cardiac EKG monitoring & 2 \\
\hline & Parenteral pain medication & \\
\hline \multirow{4}{*}{$\begin{array}{l}3 \\
3\end{array}$} & requirement & 0 \\
\hline & Support for ADLs & 27 \\
\hline & Subtotal & $56(3 \%)$ \\
\hline & Total patients with at least $1 \mathrm{Cl}$ & $1950(56 \%)$ \\
\hline
\end{tabular}

$\mathrm{ADLS}=$ activities of daily living; $\mathrm{Cl}=$ critical intervention; $\mathrm{CPR}=$ cardiopulmonary resuscitation; EKG = electrocardiogram; IV = intravenous; $\mathrm{PPV}=$ positive pulmonary ventilation.

*Hierarchically ordered for highest criticality for each patient.

**Adjusted for sampling frequency among sites.

of only half the offline licensed beds for the first 24 hours, but we assumed all licensed beds were available within 48 hours. To correspond patient-based sampling with bed equivalents, patient proportionate data were applied to the average floor census (Table 1). For example, if $33 \%$ of patients were classified as early discharges, $33 \%$ of average floor census was the estimated bed availability.

Net surge capacity was calculated by subtracting from gross surge capacity the estimated bed requirement from expected nonelective (emergency) admissions, unrelated to the disaster. Emergency admissions were acquired from the sampled services' 
official census data during the study period. The estimated capacity consumed by nonelective admissions was further adjusted for actual discharge patterns similarly obtained (Table 1). Because routine emergency department (ED) visits and admissions are known to decrease during times of "disasters," 11 a conservative $75 \%$ of routine emergency admission volume was used for calculations. The effects of varying volumes of routine nonvictim emergency admissions were determined for $25 \%$ to $100 \%$ of experienced volume as well. The projected gross and net surge capacities potentially attained were calculated using staffed study beds as the denominator (Table 1), the standard figure used to measure capacity. ${ }^{12}$ It was assumed that all "elective admissions" could be postponed after 24 hours during a significant disaster. Surge capacity was determined for each of the 4 days. To account for the oversampling at the teaching affiliate and community hospitals, the results were adjusted based on the relative sampling frequency.

\section{RESULTS}

Although facility size varied, the proportion of beds suitable for study was similar for the academic, teaching affiliate, and community hospitals $(68 \%, 73 \%$, and $73 \%$, respectively), as was the proportion of staffed beds and average floor census (Table 1).

There were 4781 patients identified during $\mathrm{T}_{0}$ sampling. Of these, 504 did not have complete data available. A further 786 patients were excluded because they were discharged on $\mathrm{T}_{0}$. Accordingly, the detailed study set comprised 3491 discrete patients whose characteristics varied significantly by hospital (Table 2). The median number of days in the hospital at $T_{0}$ was 3 (interquartile range $1-7$ ). Case mix of the sample was similar to the national hospital discharge data. ${ }^{13}$ Length of stay (LOS) ranged from 3.7 to 4.5 days (Table 1). Overall LOS nationally at the time was 4.8 days. ${ }^{12}$

There were 7386 Cls performed on 1950 (56\%) patients during the 4-day evaluation period (Table 3). Most (59\%) Cls were initiated before and continued beyond $\mathrm{T}_{0}$. Of the remaining CIs, $21 \%, 10 \%, 8 \%$, and $3 \%$ were initiated on days $1,2,3$, and 4, respectively. There were 1541 (44\%) patients who had no CIs during the evaluation period. Of these, 562 (37\%) had a CI initiated before, but discontinued before, $\mathrm{T}_{0}$ enrollment. These patients thus met criteria for appropriate early discharge. Only 128 (8\%) patients without a CI during the 4-day evaluation period ultimately had at least $1 \mathrm{CI}$ performed later in their hospital course, with most (95) of these initiated at least 6 days beyond $T_{0}$.

Most CIs were either of major (40\%) or moderate (57\%) importance (Table 4). Patients who were considered suitable for early discharge were $40 \%, 47 \%$, and $59 \%$ of the sample for the academic, teaching affiliate, and community hospitals, respectively.

The likelihood of not requiring a CI or being discharged during the evaluation period varied somewhat by patients' primary condition: $61 \%$ psychiatric, $61 \%$ oncological, $71 \%$ surgical, 76\% medical, and 93\% obstetrical.

\section{Projection of Potential Surge Capacity}

Figure 1 shows the potential surge capacity creation for each day, detailing the contribution of each action. Given the mean floor census of $82 \%$, each site had on average $18 \%$ readily available capacity at $T_{0}$ from staffed unoccupied beds (Table 1). An additional 5\% to 9\% of capacity, depending on the site, could be made available if all unstaffed licensed beds could be resourced (Table 1). In the academic, affiliate, and community hospitals, 33\% (95\% CI 29\%-36\%), 39\% (95\% CI $33 \%-45 \%$ ), and $48 \%$ (95\% CI $41 \%-56 \%$ ) of beds, respectively, could be made available by early discharge on $T_{0}$ (Fig. 1). Routine (actual) discharges among patients who were not suitable for early discharge (ie, experienced a CI, but discharged) would account for a further 21\% (95\% CI 18\%-24\%), 30\% (95\% CI 25\%-36\%), 25\% (95\% CI 19\%$32 \%)$ bed capacity, respectively. Gross surge capacity available from all actions peaked at 77\% (95\% CI 73\%-80\%), 95\% (95\% CI 92\%-98\%), and 103\% (95\% CI 88\%-118\%) of baseline staffed beds, respectively. However, net surge capacity (likely availability for disaster victims only) was $66 \%$ (95\% CI 63\%-70\%), $71 \%$ (95\% CI 66\%-77\%), and $81 \%$ (95\% CI $75 \%-87 \%$ ), respectively (Fig. 1). Each $25 \%$ reduction or increase in nonelective admissions results in a net change of $3 \%$ ( $95 \%$ CI $0 \%-6 \%), 8 \%$ (95\% CI 4\%-12\%),

\section{TABLE 4}

Critical Interventions (CIs) Required During Study Period at 3 Hospitals*

\begin{tabular}{|c|c|c|c|c|}
\hline & Academic Center, N (\%) & Teaching Affiliate, N (\%) & Community Hospital, N (\%) & Adjusted Total, ${ }^{* *} \mathbf{N}(\%)$ \\
\hline \multicolumn{5}{|l|}{$\mathrm{Cl}$} \\
\hline Major importance & $351(26 \%)$ & $180(17 \%)$ & $167(16 \%)$ & $783(22 \%)$ \\
\hline Moderate importance & $444(33 \%)$ & $344(32 \%)$ & $276(26 \%)$ & $1111(32 \%)$ \\
\hline Lower importance & $17(1 \%)$ & $35(3 \%)$ & $1(0 \%)$ & $56(2 \%)$ \\
\hline Any $\mathrm{Cl}$ (total) & $812(60 \%)$ & $559(53 \%)$ & $444(41 \%)$ & $1950(56 \%)$ \\
\hline No $\mathrm{Cl}$ performed & $540(40 \%)$ & $503(47 \%)$ & $633(59 \%)$ & $1541(44 \%)$ \\
\hline Total & 1352 & 1062 & 1077 & 3491 \\
\hline
\end{tabular}

*Hierarchically ordered for highest criticality for each patient.

${ }^{* *}$ Adjusted for sampling frequency among sites. 
FIGURE 1

Potential surge capacity. Gross surge capacity and component contribution are shown in histogram. Net surge capacity, which accounts for estimated routine nonvictim emergency admissions, is shown as yellow background to the bars. TO = initial time of catastrophic event

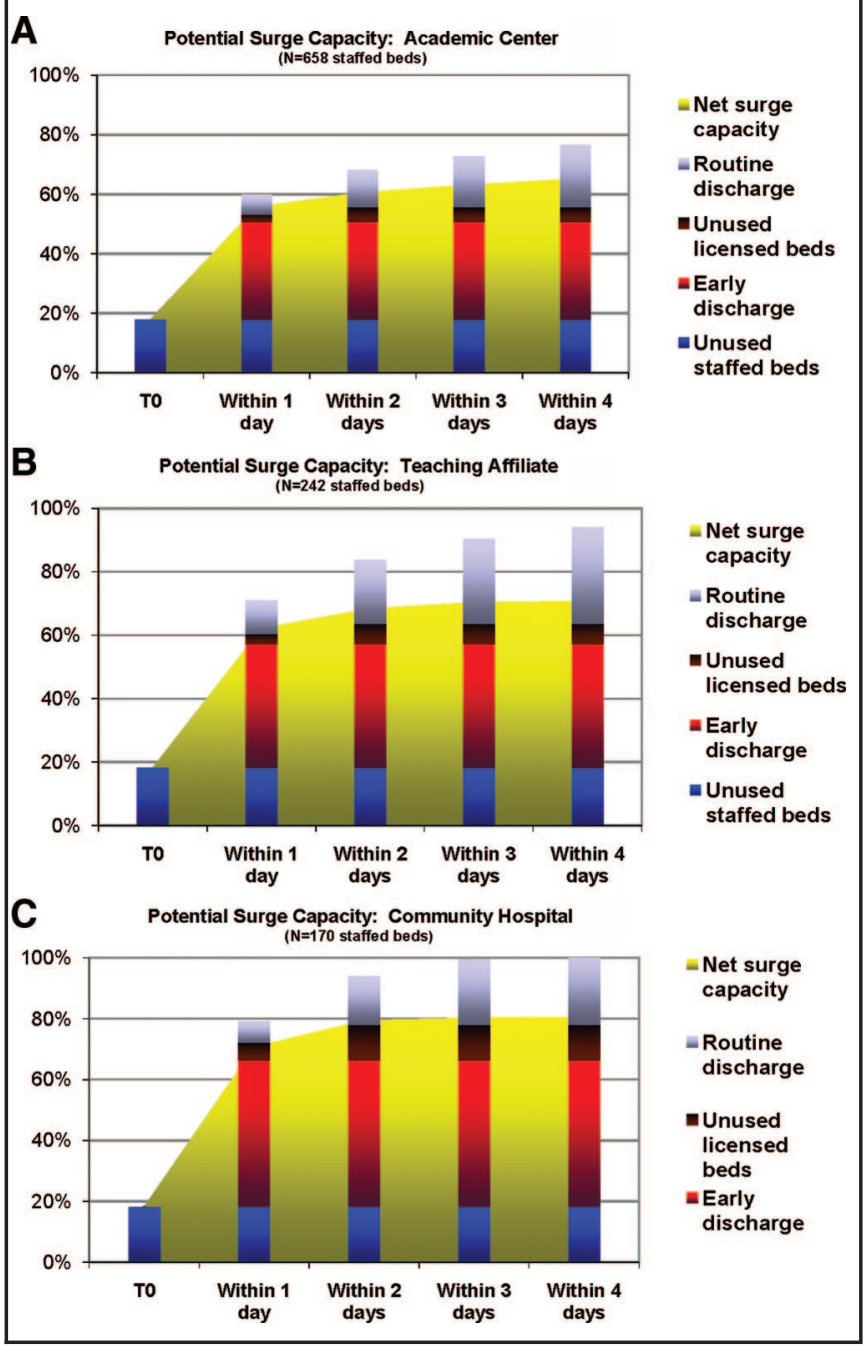

and $7 \%(95 \%$ CI 3\%-11\%) in net surge capacity, respectively. Reverse triage comprised the majority (50\%, 55\%, $59 \%$ ) of surge bed creation.

\section{DISCUSSION}

We believe this study challenges the inadequacy of inpatient surge capacity, at least for catastrophic events with short duration impact. Although varying somewhat among facilities, the potential effect size of realizable surge capacity was considerable, ranging from $77 \%$ to more than $100 \%$ for gross capacity, and $66 \%$ to $81 \%$ for net surge capacity. Whereas net surge capacity provides a sense of bed available strictly for disaster victims, gross capacity provides an estimate compatible with a utilitarian ethics framework. ${ }^{7,8}$
The concept of reverse triage advances the utilitarian approach. ${ }^{8}$ Disaster victims, those presenting with unrelated emergencies, and inpatients can be considered equally for allocation of scarce resources. Homeland Security Presidential Directive-21 also calls for this approach. ${ }^{3}$ Others have advanced a similar notion for the distribution of mechanical ventilation and other scarce ICU resources during times of overwhelming need. ${ }^{14-16}$ Applying the concept of reverse triage had the greatest effect of creating new capacity in each facility. Opinion-based survey assessments found significant capacity augmentation from early discharge if community resources were available. ${ }^{17,18}$ However, we believe our study represents the first empiric evidence for the potential of this strategy. An even larger percentage of patients could be sent home safely or avoid admission should the concept of "hospital at home" be available during a disaster. ${ }^{19}$ Thus, reverse triage offers an important new approach in the creation of surge capacity, requiring no substantial resource increment.

Among those who appeared appropriate for early discharge, $8 \%$ in fact required a $\mathrm{CI}$ beyond 96 hours. Given that the vast majority were initiated 6 or more days out, one can argue that the majority of this group would still have been safe for 96 hours in the community. The aggregate risk of early discharge (at least to low-acuity settings) for this subcohort of patients until the medical community recovers, appears acceptable from the utilitarian perspective. ${ }^{8,9}$ Previous work indicated a risk tolerance for untoward events due to early discharge of up to $12 \%$ if necessary. ${ }^{8}$

Our data revealed some unexpected results. Filling open staffed beds brought considerable contribution to surge creation, whereas opening unstaffed licensed beds contributed less. Unstaffed licensed beds were included in the model because exercising crisis-appropriate (sufficiency) care is an increasingly acceptable stand-alone hospital response. ${ }^{20-23}$ Routine daily discharges for patients not deemed initially safe for discharge also contribute substantially to potential surge.

A key to surge capacity is cancellation of elective admissions, which is readily achieved. ${ }^{10}$ Our model conservatively assumed elective admission cancellations only after the first 24 hours. Nonelective admissions are also expected to be lower than routine. High-acuity visits to EDs during the 2002-2003 severe acute respiratory syndrome (SARS) epidemic decreased by $37 \%$ in the greater Toronto, Canada, area, although the related decrease in emergency admissions is unclear. ${ }^{10}$ However, a similar study in Taiwan showed a virtual 1:1 relation in the decreased ED visits to decreased admissions during the SARS epidemic. ${ }^{24}$ The 1994 Northridge, California, earthquake experience suggests that ED visits for traditional conditions (eg, respiratory, fever, gastrointestinal) decrease after a disaster. ${ }^{25}$ Furthermore, many elective admissions are processed through EDs for expediency and insurance concerns, ${ }^{1}$ inflating emergency admissions during normal times.

Finally, we studied a system of 3 different facilities to gain an understanding of potential differences in the creation of surge 
capacity. The experience to date, including the World Trade Center catastrophe, is that institutions in closest proximity to the disaster are the ones to be overwhelmed. ${ }^{26}$ Other centers may be called into service to accept specialty transfer patients. With such high levels of capacity potentially available, a tertiary care center could transfer patients to a lower acuity center as a means to augment its high capability capacity further. Although mass evacuations, organized and ad hoc, have occurred, 27,28 the logistics of mass transfers during widespread crisis have not been addressed well in most institutions.

In our model, the near full realization of potential surge capacity occurs within 24 to 48 hours. Being conservative, we assumed that routine elective admissions on the first day would still occur, even though many such patients could also be immediately discharged. We further assumed that only $50 \%$ of unstaffed licensed beds could be resourced within 24 hours, reasoning that it would require up to 2 days to staff appropriately or apply crisis-appropriate care. We also did not account for patients who could be transferred to low-acuity settings or hospital at home, and we did not consider resource intensive capacity modulations, including the use of unlicensed beds. ${ }^{2,4-7}$ An even larger percentage of patients could be safely sent home or avoid admission, should the concept of hospital at home be available during a disaster. ${ }^{19}$

Still, the data presented should be approached with some caution. The study involved only a single health care system. Nonetheless, each hospital has a unique organization and constituency and is thus representative of many US hospitals. Occupancy rates at all 3 hospitals are considered ceilings for efficiency-much higher than occupancy rates $(69 \%-75 \%)$ experienced across the country in 2005.12 Accordingly, augmenting capacity in the study hospitals would generally be a greater challenge than the average US hospital experience.

No system to date has outright validated our approach using CIs as a proxy measure of potential untoward events. The concept was, however, developed and unanimously approved by a multidisciplinary panel, ${ }^{8}$ and the derived data are in the same order as other studies based on opinion. ${ }^{13,14}$ Finally, the present report does not provide a framework to predict which patients are unlikely to require a CI for several ensuing days, but it does show that if a system predicting risk can be harnessed, it would be a powerful tool. The authors are engaged in work that allows this type of assessment in rapid fashion similar to other risk-predictive instruments. ${ }^{29-31}$ If such a system could be developed, then the national Hospital Available Beds for Emergencies and Disasters system, which monitors available beds in real time, ${ }^{32}$ could incorporate the concepts studied here to estimate potential medical surge at the national, regional, and local levels.

We did not consider ICUs, newborn nurseries, or pediatrics. Although the reverse triage concept is the same for these, previous work was insufficient to allow the methodology to be applied. Only the academic center has a significant pro- portion of pediatric patients, and almost all of these patients are in a distinct building within the medical complex. More important, this study does not and was not designed to address capacity concerns for ICU beds, ancillary studies, and operative and other specialty care. ${ }^{33,34}$ Despite the apprehension, ${ }^{4}$ such concerns have not been shown as a true limitation in major catastrophic events such as the World Trade Center disaster and other major events. ${ }^{35,36}$ Finally, as stated from the outset, the concept studied here may not lend itself well to a prolonged event of a biologic nature such as pandemic influenza. However, the concept may indeed apply to containable epidemics with wide-reaching effects as was experienced during the SARS epidemic in Toronto.

\section{Conclusions}

We believe this investigation represents the first empirical study to address medical surge capacity. Creation of medical surge capacity may be greater than previously believed. Reverse triage, if appropriately harnessed, can significantly augment capacity without corresponding increase in resources. Methods to implement reverse triage and identify patients suitable for safe early discharge are being developed.

\section{About the Authors}

Drs Kelen, McCarthy, and Hsu, and Mr Krauss, Ms Ding, Ms Shahan, and Mr Scheulen are with the Department of Emergency Medicine, Johns Hopkins University School of Medicine; Dr Li is with the Department of Anesthesiology, Columbia University College of Physicians and Surgeons; and Dr Green is with the Department of Emergency Medicine, New York University Medical College.

Address correspondence and reprint requests to Dr Gabor D. Kelen, Professor and Chair, Department of Emergency Medicine, 1830 E Monument St, Suite 6-100, Baltimore, MD, 21287 (e-mail: gkelen1@jhmi.edu).

\section{Authors' Disclosures}

The authors report no conflicts of interest.

ISSN: 1935-7893 (C) 2009 by the American Medical Association and Lippincott Williams \& Wilkins.

DOI: 10.1097/DMP.0b013e3181a5e7cd

\section{REFERENCES}

1. Committee on the Future of Emergency Care in the United States. Hospital Based Emergency Care at the Breaking Point. Future of Emergency Care Series. Washington, DC: National Academies Press; 2006.

2. Health Care at the Crossroads: Strategies for Creating and Sustaining Community-wide Emergency Preparedness Systems. Joint Commission on Accreditation of Healthcare Organizations Web site. 2003. http://www. jointcommission.org/PublicPolicy/Emergency_Preparedness.htm. Accessed September 16, 2008.

3. Homeland Security Presidential Directive/HSPD-21. Public Health and Medical Preparedness. October 2007. http://www.dhs.gov/xabout/laws/ gc_1219263961449.shtm\#1. Accessed September 16, 2008.

4. Kaji A, Koenig KL, Bey T. Current hospital disaster preparedness. JAMA. 2007;298:2188-2190.

5. Hick JL, Hanfling D, Burstein JL, et al. Health care facility and community strategies for patient care surge capacity. Ann Emerg Med. 2004:44:253-261.

6. Revised Chapter. Emergency Management. Long Term Care Accreditation Program. February 13, 2009. http://www.jointcommission.org/NR/ 
rdonlyres/8C1D9673-297B-4B90-97D1-299767404CC9/0/B_RevisedChapter_ LTC_EM_20090213.pdf. Accessed March 26, 2009.

7. Kelen GD, McCarthy ML. The science of surge. Acad Emerg Med. 2006;13:1089-1094.

8. Kelen GD, Kraus C, McCarthy ML, et al. Inpatient disposition classification for the creation of hospital surge capacity: a multiphase study. Lancet. 2006;368:1984-1990.

9. Kraus CK, Levy F, Kelen GD. Lifeboat ethics: considerations in the discharge of inpatients for the creation of hospital surge capacity. Disaster Med Public Health Preparedness. 2007;1:51-56.

10. Stratton SJ, Tyler RD. Characteristics of medical surge capacity demand for sudden-impact disasters. Acad Emerg Med. 2006;13:1193-1197.

11. Schull MJ, Stukel TA, Vermeulen MJ, et al. Effect of widespread restrictions on the use of hospital services during an outbreak of severe acute respiratory syndrome. CMAJ. 2007;176:1827-1832.

12. Health, United States, 2007: With Chartbook on Trends in the Health of Americans Including Spreadsheets and Charts. DHHS publication no. (PHS) 2007-1232. Hyattsville, MD: National Center for Health Statistics; 2007.

13. Centers for Disease Control and Prevention. National Health Statistics Report: 2006 National Hospital Discharge Survey. Atlanta: CDC; 2008: pp. $1-20$.

14. Hick JL, O'Laughlin DT. Concept of operations of triage of mechanical ventilation in an epidemic. Acad Emerg Med. 2006;13:223-229.

15. Powell T, Christ KC, Birkhead GS. Allocation of ventilators in a public health disaster. Disaster Med Public Health Preparedness. 2008;2:20-26.

16. Devereaux AV, Christian MD, Sandrock CE, et al. Definitive care for the critically ill during a disaster: a framework for allocation of scarce resources in mass critical care. Chest 2008:133:51S-66S.

17. Davis DP, Poste JC, Hicks T, et al. Hospital bed surge capacity in the event of a mass-casualty incident. Prehosp Disaster Med. 2005;20:169_ 176.

18. Challen K, Walter D. Accelerated discharge of patients in the event of a major incident: observational study of a teaching hospital. BMC Public Health. 2006;6:108.

19. Shepperd S, Doll H, Agnus RM, et al. Admission avoidance hospital at home. Cochrane Database Syst Rev. 2005;20:CD000356.

20. Joint Commission on Accreditation of Healthcare Organizations. Surge Hospitals: Providing Safe Care in Emergencies. 2006. http:// www.jointcommission.org/NR/rdonlyres/802E9DA4-AE80-4584-A20548989C5BD684/0/surge_hospital.pdf. Accessed March 19, 2009.

21. Department of Defense Policy for Prioritizing Delivery of Medical Care During Pandemics and Other Public Health Emergencies of National Significance. HA Policy 08-110, September 1, 2008. http://mhs.osd.mil/ Content/docs/pdfs/policies/2008/08-010.pdf. Accessed March 19, 2009.

22. Altered Standards of Care in Mass Casualty Events. AHRQ publication no. 05-0043. Rockville, MD: Agency for Health Care Research and Quality; 2005.

23. Kanter RK, Moran JR. Pediatric hospital and intensive care unit capacity in regional disasters: expanding capacity by altering standards of care. Pediatrics. 2007;119:94-100.

24. Tsai MC, Arnold JL, Chuang CC, Chi CH, Liu CC, Yang YJ. Impact of an outbreak of severe acute respiratory syndrome on a hospital in Taiwan, ROC. Emerg Med J. 2004;21:311-316.

25. Salinas C, Salinas C, Kurata J. The effects of the Northridge earthquake on the pattern of emergency department care. Am J Emerg Med. 1998; $16: 254-256$

26. Cushman JG, Pachter LH, Beaton HL. Two New York City hospitals surgical response to the September 11, 2001, terrorist attack in New York City. J Trauma. 2003;54:147-155.

27. Cocanour CS, Allen SJ, Mazabob J, et al. Lessons learned from the evacuation of an urban teaching hospital. Arch Surg. 2002;137:1141-1145.

28. Schultz CH, Koenig KL, Lewis RJ. Implications of hospital evacuation after the Northridge, California, earthquake. N Engl J Med. 2003;348: 1349-1355.

29. Fine MJ, Auble TE, Yealy DM, et al. A prediction rule to identify low-risk patients with community-acquired pneumonia. N Engl J Med. 1997;336:243-250.

30. Le Gall JR, Lemeshow S, Saulnier F. A new simplified acute physiology score (SAPS II) based on a European/North American multicenter study. JAMA. 1993;270:2957-2963.

31. Knaus WA, Wagner DP, Draper EA, et al. The APACHE III prognostic system. Risk prediction of hospital mortality for critically ill hospitalized adults. Chest. 1991;100:1619-1636.

32. Agency for Healthcare Research and Quality. National Hospital Available Beds for Emergencies and Disasters (HAvBED) System. Final Report. December 2005. http://www.ahrq.gov/prep/havbed. Accessed December 10, 2008.

33. Traub M, Bradt DA, Joseph AP. The surge capacity for people in emergencies (SCOPE) study in Australasian hospitals. Med J Aust. 2007;186:394-398.

34. Einav S, Aharonson-Daniel L, Weissman C, Freund HR, Peleg K. In-hospital resource utilization during multiple casualty incidents. Ann Surg. 2006;243:533-540.

35. Jordan MH, Hollowed KA, Turner DG, Wang DS, Jeng JC. The Pentagon attack of September 11, 2001: a burn center's experience. J Burn Care Rehabil. 2005;26:109-116.

36. Cairns BA, Stiffler A, Price F, Peck MD, Meyer AA. Managing a combined burn trauma disaster in the post-9/11 world: lessons learned from the 2003 West Pharmaceutical plant explosion. J Burn Care Rehabil. 2005;26:144-150. 